$1-2020$

\title{
The Use of Cementless Components Does Not Significantly Increase Procedural Costs in Total Knee Arthroplasty
}

\author{
Samantha Harrer \\ Thomas Jefferson University, samantha.harrer@jefferson.edu \\ Michael Yayac, MD \\ Thomas Jefferson University, michael.yayac@jefferson.edu \\ William J. Hozack, MD \\ Thomas Jefferson University \\ Javad Parvizi, MD, FRCS \\ Thomas Jefferson University, Javad.Parvizi@jefferson.edu \\ P. Maxwell Courtney, MD \\ Thomas Jefferson University, paul.courtney@jefferson.edy \\ Follow this and additional works at: https://jac.jefferson.edu/si_ctr_2022_phase1 \\ Part of the Orthopedics Commons, and the Translational Medical Research Commons \\ Let us know how access to this document benefits you
}

\section{Recommended Citation}

Harrer, Samantha; Yayac, MD, Michael; Hozack, MD, William J.; Parvizi, MD, FRCS, Javad; and Courtney, MD, P. Maxwell, "The Use of Cementless Components Does Not Significantly Increase Procedural Costs in Total Knee Arthroplasty" (2020). Phase 1. Paper 57.

https://jdc.jefferson.edu/si_ctr_2022_phase1/57

This Article is brought to you for free and open access by the Jefferson Digital Commons. The Jefferson Digital Commons is a service of Thomas Jefferson University's Center for Teaching and Learning (CTL). The Commons is a showcase for Jefferson books and journals, peer-reviewed scholarly publications, unique historical collections from the University archives, and teaching tools. The Jefferson Digital Commons allows researchers and interested readers anywhere in the world to learn about and keep up to date with Jefferson scholarship. This article has been accepted for inclusion in Phase 1 by an authorized administrator of the Jefferson Digital Commons. For more information, please contact: JeffersonDigitalCommons@jefferson.edu. 


\section{SI/CTR Abstract}

\section{The Use of Cementless Components Does Not Significantly Increase Procedural Costs in Total Knee Arthroplasty}

\section{Samantha Harrer, BS, Michael Yayac, MD, William J. Hozack, MD, Javad Parvizi, MD, FRCS, P. Maxwell Courtney ${ }^{\star}$, MD}

$\left(^{*}\right)$ indicates primary project advisor

Introduction: Modern cementless total knee arthroplasty (TKA) designs have shown promising early clinical success; however, concerns exist regarding the higher cost of the cementless implants. The purpose of this study is to evaluate the total facility cost of cementless vs traditional cemented TKA along with the effect of cementless fixation on short-term outcomes.

Methods: We reviewed a consecutive series of patients between 2015 and 2017 who underwent either cementless or cemented primary TKA. Itemized facility costs were calculated for every procedure using a time-driven activity-based costing algorithm. Controlling for demographic variables and medical comorbidities, we performed a multivariate analysis to identify independent risk factors for facility costs following TKA. Short-term outcome metrics including complications, readmissions, and patient-reported outcomes were compared between groups.

Results: Among the 2426 primary TKA patients in this study, 119 (4.91\%) were performed using cementless implants. When compared to cemented TKA, cementless TKA patients had higher implant costs, but lower supply costs and lower operating room 
personnel costs. When controlling for confounding variables, cementless fixation did not have a significant effect on total facility cost or outcomes.

Discussion: The use of cementless TKA implants did not significantly increase total procedural costs when compared to traditional cemented TKA components at our institution. Our data suggest that the increased cost of a cementless implant is recouped through savings in cost of cement and supplies, as well as shorter operative times. The authors encourage investigators at other institutions to use the authors' methodology to evaluate (preferably in a prospective manner) whether the findings from this study can be corroborated. 